\title{
Adherence To Infection Prevention Standard Precautions Among Health Care Workers In Embu Level 5 Hospital-Embu County Kenya
}

\author{
Richard Mulu Musyoki ${ }^{1}$, Dr.Stanley Kimuhu ${ }^{2}$, and Dr.Peterson Warutere ${ }^{3}$ \\ Research Scholar ${ }^{1}$, Practising Doctor ${ }^{2-3}$ \\ Department of Community Health and Epidemiology \\ School of Public Health and Applied Human Sciences \\ Kenyatta University \\ Nairobi, Kenya
}

\begin{abstract}
Standard precautions are a set of infection control practices used to prevent transmission of diseases that can be acquired by contact with blood, body fluids and non-intact skin. This is because it has the potential benefits of reducing disease burden on health care workers, patients, health institutions and the nation as a whole. This study was conducted with the main objective of establishing adherence to infection prevention standard precautions among health care workers in Embu Level 5 Hospital-Embu County Kenya. The study population consisted of all health workers working in Embu level 5 Hospital for more than 6 months. Data collection involved use of a pre-tested questionnaire for quantitative data and Focused Group Discussion (FGD) guide for qualitative data. The sample size was 211 participants. Data analysis was done using SPSS version 22 while chi square test was used to compare association between variables and content analysis for qualitative data. Data collected from respondents were cleaned, coded and entered in to a computer. The study found out that the demographic factors significantly associated with the uptake of adherence to IPC include; gender ( $p=0.0408)$, job carder ( $p=0.0492)$, education $(p=0.0174)$, age $(p=0.0063)$ and work experience $(p=0.0192)$. It was also established that adhering or not adhering IPC is significantly associated with poor or good levels of injection safety ( $p<0.002)$, waste management $(p=0.012)$, PPE use $(p<0.018)$, hand hygiene $(p=0.022)$.
\end{abstract}

Key words: Health Care Workers, Infection Prevention \& Control; Post Exposure Prophylaxis.

\section{INTRODUCTION}

Standard precautions in infection prevention are guidelines that outline the minimum set of interventions that are required for prevention of transmission of microorganisms among health workers (WHO, 2014). They prevent healthcare staffs from getting infections through exposure to blood and blood products, body fluids, aerosols and needle prick injuries during working time. All staffs working in facility set up can easily contract hepatitis B, needle prick injuries, blood splash injuries or Human Immune Deficiency Virus (HIV). Percutaneous injuries can also occur where one sustains needle stick or sharps injuries (1).

Globally, potentially harmful clinical wastes accounts for $2.5 \%$ cases of HIV and $40 \%$ of Hepatitis B and C cases globally (WHO, 2014). The world health organization estimates that, 3 million out of 35 million HCWs suffer from percutaneous injuries and mostly occurring in developing countries (1).

Compliance to infection prevention standard precautions decreases cases among health care workers. These standard precautions includes hand hygiene, use of personal protective equipment (gloving, masks and gowns), safe injection practices, waste segregation and waste management (2).

In Africa, HCWs sustain 2 needle prick injuries with Nigeria, Tanzania and South Africa having approximately 2.10 needle pricks per healthcare worker. In Kenya, country profile data on infections as a result of poor adherence to infection prevention is lacking. The committee for health is responsible for ensuring training, implementation, evaluation and availability of standard precaution policy guides and adherence to the same. The national infection prevention guidelines have been developed by the ministry of public health and must be adhered to reduce the potential health effects (3). 
The main objective of this study was to examine adherence to infection prevention standard precautions among healthcare workers in Embu Level 5 Hospital-Embu County, Kenya. The specific objectives where:

a) To find out the influence of socio-demographic factors on adherence to infection prevention standard precautions among health care workers in Embu level 5 hospital.

b) To determine the level of awareness on adherence to infection prevention standard precautions among health care workers in Embu level 5 hospital.

c) To determine how attitude influence healthcare workers towards adherence to infection prevention standard precautions among health care workers in Embu level 5 hospital.

d) To determine the level of practice of infection prevention and control measures amongst healthcare workers in Embu level 5hospital.

\section{2: MATERIALS AND METHODS}

The study adopted a descriptive cross-sectional survey design. The descriptive survey design is quite appropriate for gathering information, summarizing, presenting and interpreting it for the purpose of clarification. This design was appropriate for good understanding of the adherence to infection prevention standard precautions among health care workers in Embu level 5 hospital. The dependent variable was adherence to infection prevention standard precautions, the independent variables were:

i. Socio-demographic factors which included: gender, age, education levels, job carder, and working experience.

ii. Awareness of infection prevention and standard precautions.

iii. Attitude of healthcare workers towards infection prevention.

iv. Practice of infection prevention and standard precautions which included: Hand hygiene, use of personal protective equipment's, safe administration of injections and waste segregation and management among the health care workers.

The study was carried out in Embu level 5 hospital in Embu County. These facility was selected since it's the largest in the eastern region with 816 staffs, 618 beds and 97 baby cots and an estimated 700 patients attended daily in outpatient. Embu level 5 Hospital is located along Nairobi- Meru road. It has a latitude of $0^{\circ} 31^{\prime} 52^{\prime \prime} \mathrm{S}$, longitude of $37^{\circ} 27^{\prime} 02^{\prime \prime} \mathrm{E}$ and altitude of 1406 meters above the sea level $(\mathrm{MOH}, 2021)$. The study population was doctors, nurses, clinical officers, laboratory technologists, physiotherapists and support staffs who had worked for a minimum period of six months. For quantitative data, 211 health care workers were selected to participate in the study. Embu County was purposively selected in Embu County due to low adherence rate (32\%) in Embu County health facilities. Embu Level 5 Hospital was purposively selected due to increasing none adherence to IPC among the HCWs in Embu Level 5 Hospital. A total of 211 healthcare workers were selected to participate in the study. Lastly from each department, those who had worked for more than 6 months (to minimize on recall bias) were selected to participate in the study. The research instruments consisted of observation checklist, questionnaire informant interview and focus group discussion. Interviewer administered questionnaires were used to collect quantitative data. The questionnaires were with open and closed ended questions in English. The data was coded and entered into SPSS version 22 after which data cleaning was done to ensure completeness and remove any wrongly entered character. A validation of the data was done to ensure only valid data is analyzed. Descriptive statistics used to describe the data included percentages and frequencies. For hypothesis, testing chisquare test of association was used to test association between adherence and variables deemed to affect infection prevention and control. Binary multivariate logistic regression was used to determine odds ratio, confidence interval and probabilistic values ( $\mathrm{p}$ value). The level of IPC adherence was computed using the number of HCWs who adhered/not adhered to: Hand hygiene practice, safe administration of injections practice, personal protective equipment's use, waste segregation and management.

\section{3: RESULTS AND DISCUSION}

\subsection{Introduction}

This chapter presents the results of the study as obtained from the various tools that were employed to collect and analyze both quantitative and qualitative data. Quantitative data collection was achieved through a questionnaire while qualitative data was collected using information obtained from observation checklist, key informant interview and focus group discussion.

\subsection{Influence of socio-demographic factors on adherence to infection prevention standard precautions}

From the findings, majority $152(72 \%)$ of the respondents were female. The study found out majority $55(26 \%)$ of the heath care workers where aged 35-40 years with very few 29(13.7\%) where below 25 years. On education level, 23(10.9\%) had masters, 29 participants $(13.7 \%)$ had degree, 97 participants (46\%) had diploma, $62(29.4 \%)$ had certificate. The higher one studied, the higher 
the adherence. On job carder, medical doctors had better adherence while support staffs had poor adherence.20 participants (9.5\%) were medical doctors , 132 participants (62.6\%) were nurses, 16 participants (7.6\%) were clinical officers,10 participants (4.7\%) were laboratory technologists, 8 participants $(3.8 \%)$ were physiotherapists while $25(11.8 \%)$ where support staffs. Further, the study found out majority 59(28\%) had 11-15 years of working experience. Those who had worked for long had better adherence.

Table 1: Influence of socio-demographic factors on adherence to infection prevention standard precautions

\begin{tabular}{|c|c|c|}
\hline Demographic information & $\mathrm{N}=211$ & Percentage \\
\hline \multicolumn{3}{|l|}{ Gender } \\
\hline Male & 59 & 28 \\
\hline Female & 152 & 72 \\
\hline \multicolumn{3}{|l|}{ Age brackets } \\
\hline Below 25 years & 29 & 13.7 \\
\hline $25-30$ years & 43 & 20.4 \\
\hline $30-35$ years & 44 & 20.9 \\
\hline $35-40$ years & 55 & 26.0 \\
\hline$>40$ years & 40 & 19.0 \\
\hline \multicolumn{3}{|l|}{ Education levels: } \\
\hline Masters & 23 & 10.9 \\
\hline Degree & 29 & 13.7 \\
\hline Diploma & 97 & 46.0 \\
\hline Certificate & 62 & 29.4 \\
\hline \multicolumn{3}{|l|}{ Job cadre: } \\
\hline Nurse & 132 & 62.6 \\
\hline Medical doctors & 20 & 9.5 \\
\hline Laboratory technician & 10 & 4.7 \\
\hline Clinical officer & 16 & 7.6 \\
\hline Physiotherapists & 8 & 3.8 \\
\hline Support staffs & 25 & 11.8 \\
\hline \multicolumn{3}{|l|}{ Working experience: } \\
\hline 6-11months & 26 & 12.3 \\
\hline $1-4$ years & 41 & 19.4 \\
\hline $5-10$ years & 58 & 27.5 \\
\hline $11-15$ years & 59 & 28.0 \\
\hline$>16$ years & 27 & 12.8 \\
\hline
\end{tabular}

3.3 Chi-square test of association between adherence to infection prevention standard precautions and socio-demographic factors

Along the adherence estimations, chi-square $(\lambda)$ tests of significance at $p<0.05$ were also performed where relationship of age, working experience, job carder, education level, gender and adherence to infection prevention standard precautions was found statistically significant as described in Table 4.4; Age had high significance $(\chi 2=14.3528$; $\mathrm{df}=4$; $\mathrm{p}=0.0063)$, while gender had least significance $(\chi 2=4.1831 ; \mathrm{df}=1 ; \mathrm{p}=0.0408)$

The summary of these findings is presented in Table 2. 
International Journal of Advances in Scientific Research and Engineering (ijasre), Vol 7 (7), July-2021

Table 2: Association between adherence to infection prevention standard precautions and socio-demographic factors

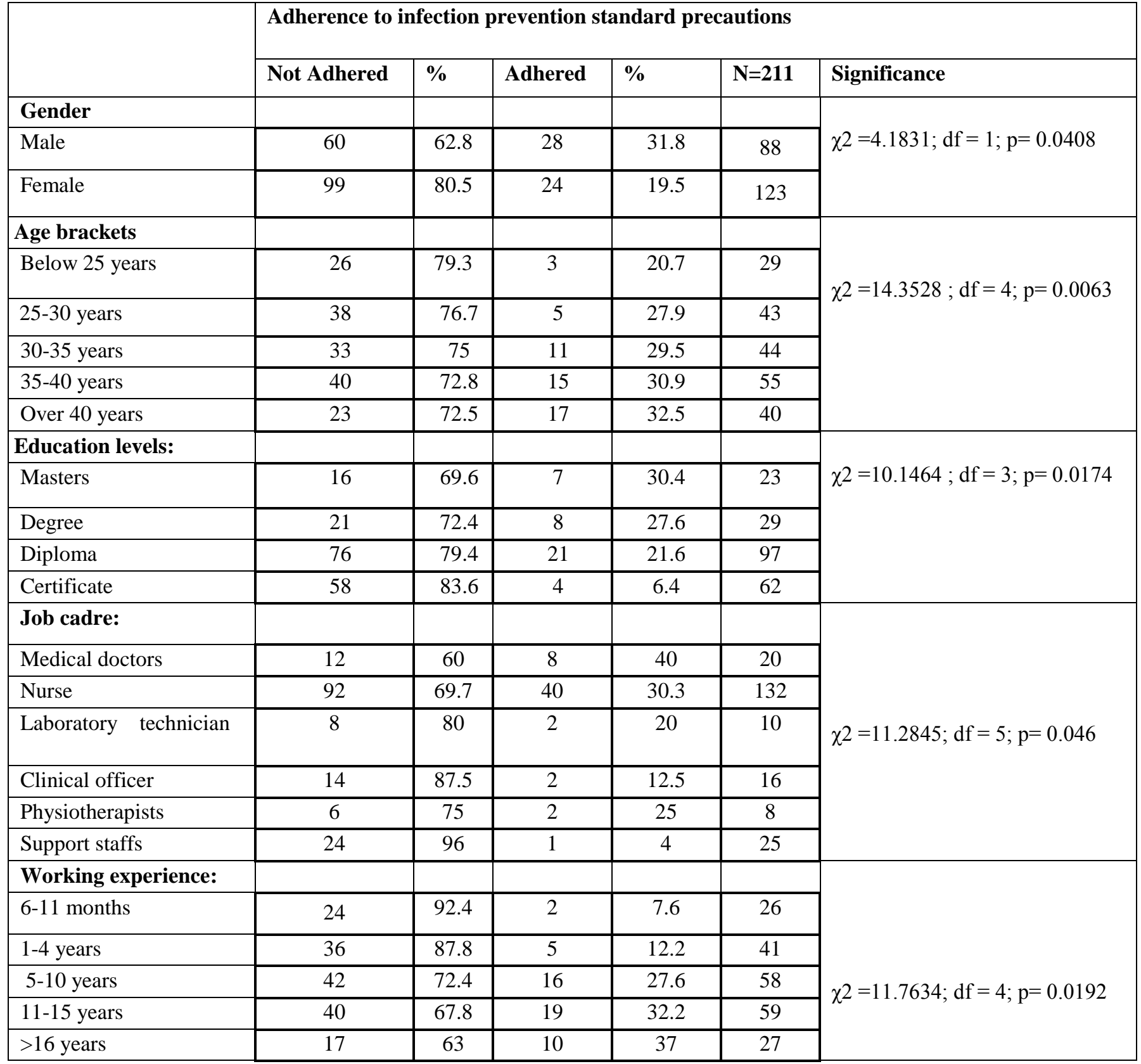

\subsection{Level of awareness on adherence to infection prevention standard precautions}

Awareness highly influenced adherence to infection prevention and standard control. This study revealed that the infection control team was not active. The current in- charge had not organized any meeting for the last one year. This was illustrated by majority (75.8\%) who reported that they were not aware of existence of infection prevention control team in the facility and majority (78.7\%) had not attended any infection prevention control meeting for the last one year. Majority (87.2\%) revealed too that the IPC team had not met during the past 12 months. 


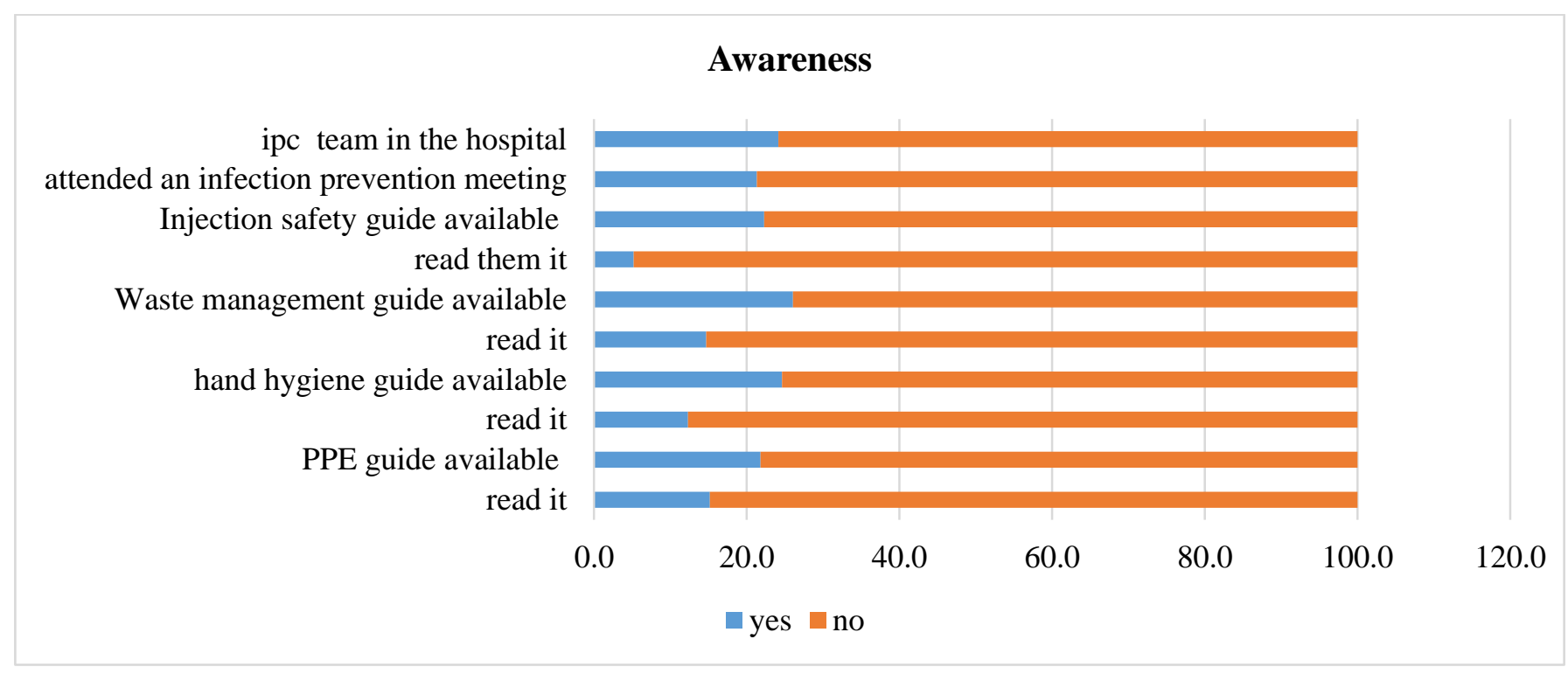

Figure1. Health care workers awareness to infection prevention standard precautions

\subsection{Influence of attitude of health care workers towards adherence to infection prevention standard precautions}

The study revealed that there was no significant relationship between attitude and adherence to infection prevention. Majority (66.8\%) strongly agreed that a new pair of gloves should be used for each new patient while majority (79.6\%) strongly that it was important for all health care workers to be vaccinated against hepatitis B with few 2(0.9\%) who disagreed. Majority $166(78.7 \%)$ strongly agreed that they should always practice hand hygiene before and after. (Table 3).

Table 3: Various aspects of attitude of health care workers towards adherence to infection prevention standard precautions

\begin{tabular}{|l|l|l|l|l|l|}
\hline & $\begin{array}{l}\text { Strongly } \\
\text { Agree }\end{array}$ & Agree & Neutral & Disagree & $\begin{array}{l}\text { Strongly } \\
\text { disagree }\end{array}$ \\
\hline Anew pair of gloves should be used for each new patient & $141(66.8 \%)$ & $67(31.6 \%)$ & $3(1.6 \%)$ & $0(0 \%)$ & $0(0 \%)$ \\
\hline Important HCWs to be vaccinated against hepatitis B & $168(79.6 \%)$ & $40(19 \%)$ & $1(0.5 \%)$ & $2(0.9 \%)$ & $0(0 \%)$ \\
\hline Always practice hand hygiene before /after gloving & $166(78.7 \%)$ & $45(21.3 \%)$ & $0(0 \%)$ & $0(0 \%)$ & $0(0 \%)$ \\
\hline Wash hands before / after every procedure & $159(75.4 \%)$ & $52(24.6 \%)$ & $0(0 \%)$ & $0(0 \%)$ & $0(0 \%)$ \\
\hline Dispose waste in right bins & $134(63.5 \%)$ & $77(36.5 \%)$ & $0(0 \%)$ & $0(0 \%)$ & $0(0 \%)$ \\
\hline Never reuse used gloves & $157(74.4 \%)$ & $54(25.6 \%)$ & $0(0 \%)$ & $0(0 \%)$ & $0(0 \%)$ \\
\hline My responsibility to comply with IPC guidelines & $161(76.3 \%)$ & $50(23.7 \%)$ & $0(0 \%)$ & $0(0 \%)$ & $0(0 \%)$ \\
\hline Always attend all IPC trainings & $137(64.9 \%)$ & $69(32.7 \%)$ & $3(1.4 \%)$ & $2(1 \%)$ & $0(0 \%)$ \\
\hline Never recap needles after use & $143(67.8 \%)$ & $67(31.7 \%)$ & $1(0.5 \%)$ & $0(0 \%)$ & $0(0 \%)$ \\
\hline
\end{tabular}

\subsection{Level of practice of infection prevention and control measures among healthcare workers}

\subsubsection{Hand hygiene practice}

Hand hygiene is the primary measure in preventing infections and is the cornerstone of good infection prevention and control (IPC) practice. The study found out there were minimal supply of soap and alcohol based hand rubs as revealed by $76.3 \%$ and $74.4 \%$ consecutively hence poor hand washing activity in the departments. Hand washing is the main stay in prevention of infection prevention. All healthcare workers are supposed to wash hands before and after activities. The healthcare workers were supposed to order for soap and hand sanitizers only twice in a week and if the consumption is high in the department and runs out of stocks, they have to wait for the following week to place another order. This led to insufficient stocks within the departments. The study revealed that majority $(78.2 \%)$ of the healthcare workers had not been trained on hand hygiene. It was noted that there were insufficient sinks in departments as revealed by $68.7 \%$ of the healthcare workers. (Figure 2). 


\section{Hand hygiene practice}

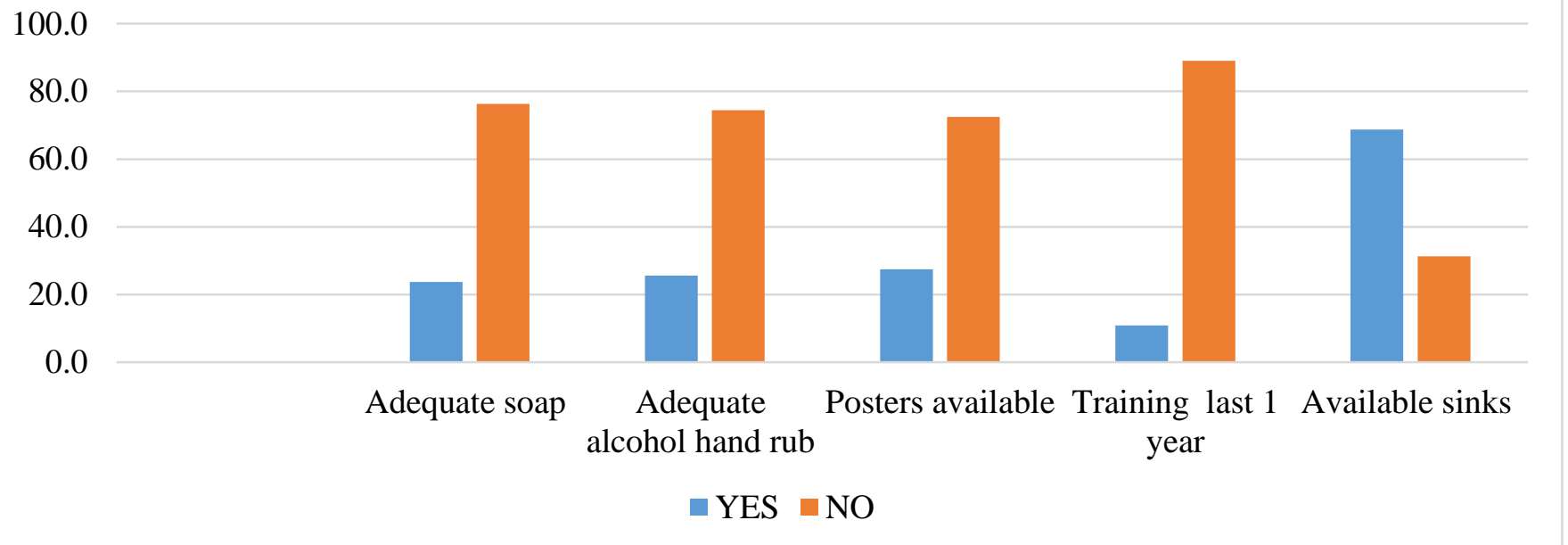

Figure 2: Aspects of hand hygiene for infection prevention and control measures among healthcare workers

\subsubsection{Use of personal protective equipment's in prevention of infection prevention}

Personal protective equipment use protects health worker as well as reduces their risk of infections. However, compliance with standard precautions on use of PPEs amongst HCWs in Embu Level 5 Hospital was observed to be poor. The study revealed that majority of the respondents $(84.4 \%)$ had not been trained for the last one year on use of PPES. The study revealed that few $(12.3 \%)$ knew about donning and doffing of PPES. PPEs were not adequate as revealed in this study. There were frequent stock outs hence support staffs had to put on torn industrial gloves or boots, some of the clinical staffs could not perform some procedures due to recurrent gloves and masks stock outs in all departments as reported by $70.1 \%$ and $71.1 \%$ consecutively. This prompted the healthcare workers to stage a strike on March, 2021 due to exposure to infections since most of the personal protective equipment's were lacking in the hospital and increased exposure to COVID 19.

PPE use

Training in PPE

Know donning and doffing PPE adequate PPEs PPES well-fitting Always use PPEs Masks adequate Gloves adequate

Aprons, coats/overalls adequate Safety boots and googles adequate

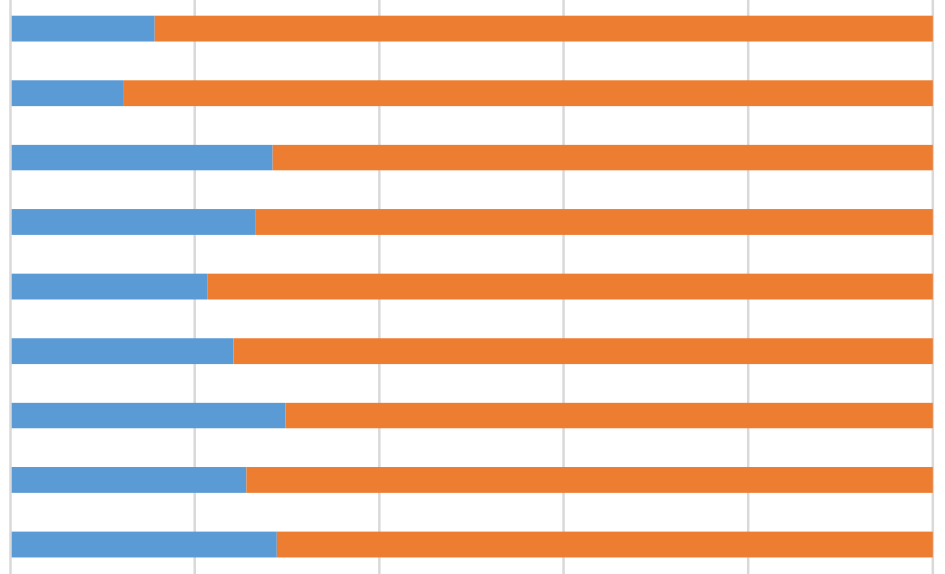
0.0
20.0
40.0
60.0
80.0
100.0
120.0
$\because \mathrm{YES} \square \mathrm{NO}$

Figure 3: Use of personal protective equipment's in infection prevention 


\subsubsection{Safe Administration of Injections by health care workers}

A sharps injury prevention program must be in place in all health care settings and all health care workers should be trained on injection safety practices. Majority (77.3\%) revealed that they had not been trained for the last 1 year. The study revealed there were no PEP guidelines available as reported by $74.4 \%$ of the respondents and hence PEP was not administered as per ministry of health guidelines. The outpatient didn't have guidelines at all and there was no documentation for anyone who had been given PEP especially after 5 pm since the CCC is closed in the evening.

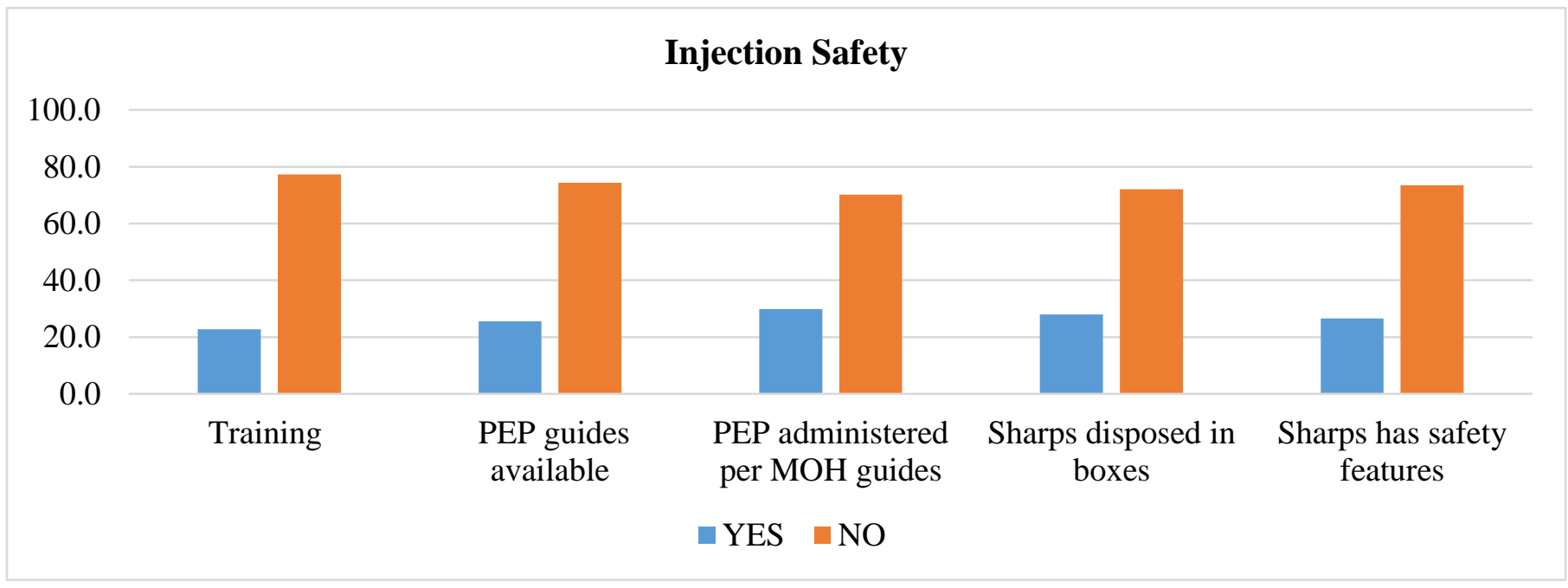

Figure 4: Safe Administration of injections by health care workers

\subsubsection{Waste segregation and waste management practice}

3.6.4.1 Waste segregation and waste management practice at ward level

The study revealed that, majority $(67.8 \%)$ of the respondents reported waste segregation was not carried out according to the set standards of operation in this hospital, majority $(88.2 \%)$ revealed the labelling of waste was also not done by trained people, majority $(83.9 \%)$ reported incinerator in the hospital was not sufficient to handle all the hospital waste to be incinerated at any given time (Figure 5).

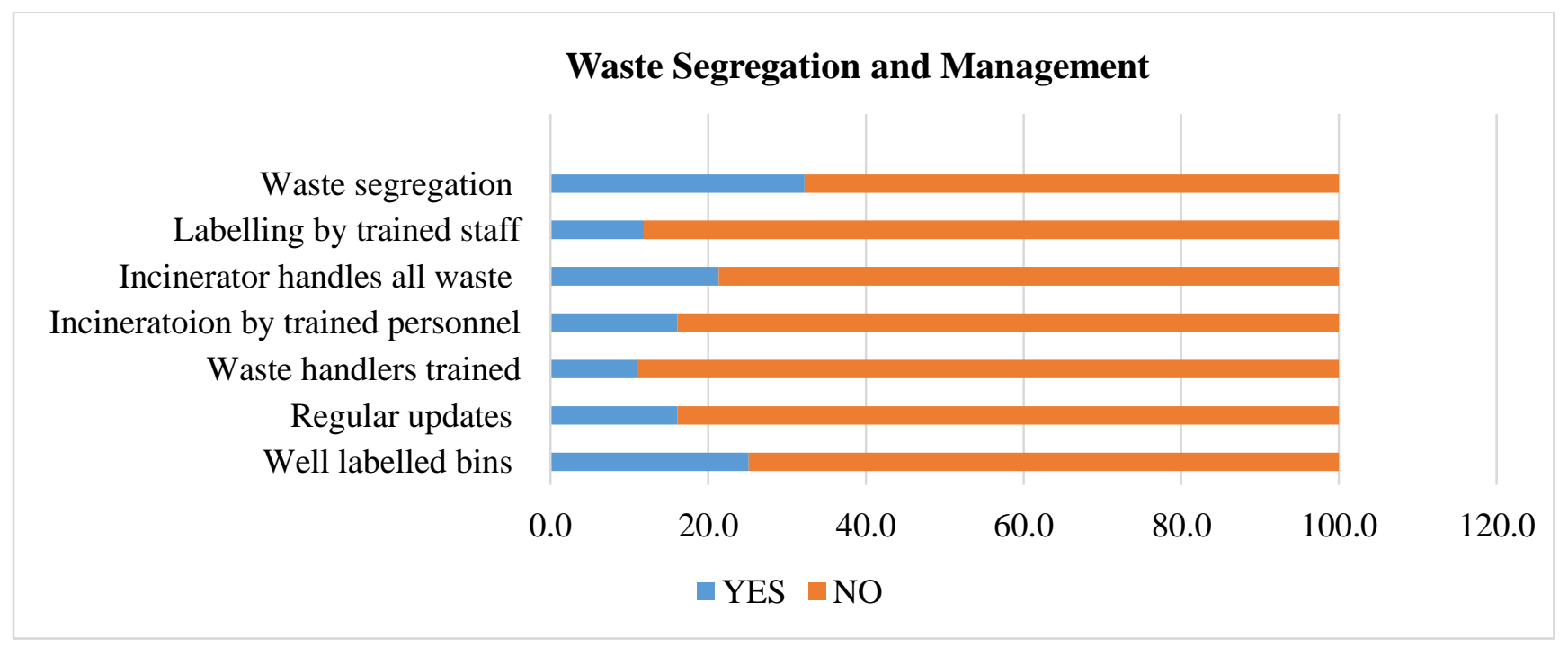

Figure 5: Questions on waste segregation and waste management practice

\subsubsection{Observation of waste segregation and management practice at ward level}

Study findings on frequency of observation for waste segregation at ward level revealed that, $9 \%$ observed waste holding area was available and big enough to accommodate all the hospital waste ,9\%) observed waste collected from waste generation point to waste storage area was done using trolleys while $16.6 \%$ noted staff collecting waste has appropriate PPES .It was also noted by $7.6 \%$ ) that there was documented evidence all staffs handling wastes having been trained on IPC while $18 \% \%$ observed safety boxes which are $2 / 3$ full where well separated and recorded. It was also observed by $6.6 \%$ that ,color coded bins where 
available in working stations while $3.8 \%$ observed that bin liners where available while $5.7 \%$ noted wastes was disposed at the right waste disposal bins and $5.7 \%$ reported bin liners where clearly labelled. Few $(8.5 \%)$ reported waste was quantified according to standards of infection prevention while $9.5 \%$ observed incinerator was in good working condition as illustrated in (Table 5).

Table4. Observation of waste segregation and management practice at ward level

\begin{tabular}{|c|c|c|}
\hline Observation- Waste segregation and management & $\begin{array}{c}\text { Frequency } \\
\mathbf{n}=\mathbf{2 1 1}\end{array}$ & Percentage \\
\hline Waste transfer / holding stations available & 19 & 9.0 \\
\hline Waste collected from waste generation point to waste storage area using trolleys & 19 & 9.0 \\
\hline Staff collecting waste has appropriate PPES & 35 & 16.6 \\
\hline Documented evidence all staffs handling wastes have been trained on IPC & 16 & 7.6 \\
\hline All safety boxes which are $2 / 3$ full are separated and recorded & 38 & 18.0 \\
\hline Adequate color coded bins are available & 14 & 6.6 \\
\hline Bin liners available & 8 & 3.8 \\
\hline Waste disposed at right coded bins & 12 & 5.7 \\
\hline The pedal bins are clearly labeled & 12 & 5.7 \\
\hline Waste quantified by standards of IPC & 18 & 8.5 \\
\hline $\begin{array}{l}\text { Incinerator in good working condition, properly sited, secured and has industrial } \\
\text { thermometer which can record up-to } 1000 \text { degrees }\end{array}$ & 20 & 9.5 \\
\hline
\end{tabular}

\subsection{Chi-square analysis of association between awareness, attitude, practice of infection prevention and IPC adherence}

Chi-square analysis of association between awareness, attitude, practice of infection prevention and IPC adherence was done. IPC adherence was found to be significantly associated with awareness $(\chi 2=12.9021$, $\mathrm{df}=1$, $\mathrm{p}$ value 0.002$)$, personal protective equipment's use $(\chi 2=9.8225, \mathrm{df}=1, \mathrm{p}$ value 0.002$)$, waste management $(\chi 210.2999, \mathrm{df}-1, p$ value 0.012$)$, injection safety $(\chi 2=8.3036 \mathrm{df}=1, \mathrm{p}$ value 0.002$)$, hand hygiene $(\chi 2=5.1084, \mathrm{df}=1, \mathrm{p}$ value 0.022$)$. Attitude $(\chi 2=0.1533, \mathrm{~d}=1, p$ value 0.577$)$ was not significantly associated with IPC adherence. The results summary is presented in table 6below.

Table 5: Chi-square analysis of association between awareness, attitude, practice of infection prevention and IPC adherence among healthcare workers in Embu level 5 hospital, Embu County

\begin{tabular}{|c|c|c|c|c|}
\hline \multicolumn{2}{|l|}{ VARIABLE } & \multicolumn{2}{|c|}{ IPC ADHERENCE } & \multirow[t]{2}{*}{ CHI SQUARE TEST } \\
\hline & & Not achieved & Achieved & \\
\hline \multirow[t]{2}{*}{ Awareness } & Low & 122 & 30 & \multirow[t]{2}{*}{$\chi^{2}=12.9055, \mathrm{df}=1, p$ value 0.0003} \\
\hline & High & 33 & 26 & \\
\hline \multirow[t]{2}{*}{ Attitude } & Poor & 24 & 40 & \multirow[t]{2}{*}{$\chi^{2}=0.1532, \mathrm{~d}=1, p$ value 0.696} \\
\hline & Good & 51 & 96 & \\
\hline \multirow[t]{2}{*}{ Safe administration of injections } & Poor & 123 & 25 & \multirow{2}{*}{$\begin{array}{l}\chi 2=8.2961 \\
\mathrm{df}=1, p \text { value } 0.0039\end{array}$} \\
\hline & Good & 41 & 22 & \\
\hline \multirow[t]{2}{*}{ Waste segregation/management } & Poor & 126 & 25 & \multirow[t]{2}{*}{$\chi 28.5677, \mathrm{df}-1, p$ value 0.003} \\
\hline & Good & 39 & 21 & \\
\hline \multirow[t]{2}{*}{ PPES } & Poor & 123 & 28 & \multirow[t]{2}{*}{$\chi 2=10.6450, \mathrm{df}=1, p$ value 0.001} \\
\hline & Good & 36 & 24 & \\
\hline \multirow[t]{2}{*}{ Hand hygiene } & Poor & 113 & 24 & \multirow[t]{2}{*}{$\chi 2=5.1049, \mathrm{df}=1, p$ value 0.0239} \\
\hline & Good & 51 & 23 & \\
\hline
\end{tabular}

\subsection{Multivariate logistic regression}

Logistic regression analysis was used to establish the predictors of adherence to IPC .Results from the multivariate logistic regression are presented in table 4.16 . 
International Journal of Advances in Scientific Research and Engineering (ijasre), Vol 7 (7), July-2021

Table 6: Multivariate logistic regression

\begin{tabular}{|c|c|c|c|c|c|}
\hline Variables & Odds & $95 \% \mathrm{CI}$ & & Std. Error & P-value \\
\hline & & Lower & Upper & & \\
\hline \multicolumn{6}{|l|}{ Gender (ref: Female) } \\
\hline Male & 0.546 & 0.27 & 1.103 & 0.359 & 0.032 \\
\hline \multicolumn{6}{|l|}{ Age (ref: Below 25 years) } \\
\hline $25-30$ years & 0.243 & 0.008 & 1.482 & 1.748 & 0.019 \\
\hline $30-35$ years & 0.795 & 0.029 & 2.077 & 1.696 & 0.022 \\
\hline $35-40$ years & 1.459 & 0.188 & 2.31 & 1.045 & 0.017 \\
\hline Over 40 years & 1.596 & 0.12 & 2.26 & 1.321 & 0.024 \\
\hline \multicolumn{6}{|c|}{ Education (ref: secondary) } \\
\hline Masters & 1.804 & 0.131 & 2.944 & 1.34 & 0.03 \\
\hline Degree & 0.002 & 0.001 & 0.004 & 1.774 & 0.01 \\
\hline Diploma & 0.001 & 0.001 & 0.007 & 1.773 & 0.04 \\
\hline \multicolumn{6}{|c|}{ Job Carder (ref: Support staffs) } \\
\hline Medical doctors & 4.859 & 0.396 & 5.659 & 1.279 & 0.017 \\
\hline Nurses & 1.462 & 0.147 & 4.558 & 1.173 & 0.046 \\
\hline Laboratory technologist & 1.156 & 0.07 & 2.118 & 1.431 & 0.019 \\
\hline Clinical officers & 1.079 & 0.024 & 4.02 & 1.947 & 0.049 \\
\hline Physiotherapists & 1.14 & 0.021 & 2.212 & 1.211 & 0.015 \\
\hline \multicolumn{6}{|c|}{ Working experience (ref: 6-11 months) } \\
\hline $1-4$ years & 0.002 & 0.001 & 0.003 & 1.405 & 0.032 \\
\hline $5-10$ years & 0.72 & 0.068 & 3.639 & 1.205 & 0.036 \\
\hline $11-15$ years & 1.395 & 0.073 & 2.494 & 1.502 & 0.025 \\
\hline Above 16 years & 1.573 & 0.002 & 1.984 & 1.101 & 0.022 \\
\hline \multicolumn{6}{|l|}{ Awareness (ref: High) } \\
\hline Low & 0.003 & 0.001 & 0.012 & 1.735 & 0.063 \\
\hline \multicolumn{6}{|c|}{ Safe injections administration (ref: bad) } \\
\hline Good & 0.655 & 0.047 & 2.083 & 1.342 & 0.052 \\
\hline \multicolumn{6}{|c|}{ Waste segregation/management (ref: bad) } \\
\hline Good & 0.437 & 0.111 & 1.728 & 0.701 & 0.038 \\
\hline \multicolumn{6}{|l|}{ PPE use (ref: Bad) } \\
\hline Good & 0.361 & 0.001 & 2.136 & 1.067 & 0.03 \\
\hline \multicolumn{6}{|l|}{ Hand hygiene (ref: bad) } \\
\hline Good & 1.126 & 0.343 & 3.697 & 0.607 & 0.045 \\
\hline
\end{tabular}

3.9 Adherence to Infection Prevention Standard Precautions

Table 7: Adherence to infection prevention standard precautions

\begin{tabular}{|l|l|c|c|}
\multirow{4}{*}{ Safe administration of injections } & & Frequency & Percentage \\
\cline { 2 - 4 } & Not achieved & 164 & 77.7 \\
\cline { 2 - 4 } & Achieved & 47 & 22.3 \\
\hline \multirow{2}{*}{ Waste management } & Not achieved & 165 & 78.2 \\
\cline { 2 - 4 } & Achieved & 46 & 21.8 \\
\hline \multirow{2}{*}{ PPE use } & Not achieved & 159 & 75.4 \\
\cline { 2 - 4 } & achieved & 52 & 24.6 \\
\hline \multirow{2}{*}{ Adherence to IPC } & Poor & 164 & 77.8 \\
\cline { 2 - 4 } & Good & 47 & 22.2 \\
\cline { 2 - 4 } & \multicolumn{3}{|c|}{} \\
\cline { 2 - 4 } & Not achieved & 164 & 77.7 \\
\cline { 2 - 4 } & Achieved & 47 & 22.3 \\
\hline
\end{tabular}

Adherence to IPC is based on WHO (4) definition of adherence to infection prevention which includes injection safety, waste management, PPEs use, and hand hygiene. 


\subsection{CONCLUSION}

Adherence to infection prevention control and standard precautions was low. Among the social demographic factors, adherence to infection was high among the male healthcare workers, those over 40 years of age, those with masters, medical doctors and those who had working experience of more than 16 years of age. The healthcare workers awareness was found to be low too. The respondents' attitude of health care workers didn't influence adherence to IPC since most of the healthcare workers having positive attitude. On level of practice of infection prevention and control measures amongst healthcare workers: Lack of PPEs, Poor injection safety practice, lack of training on IPC and PEP guidelines unavailability led to poor IPC adherence. Poor hand hygiene practice was revealed in the study with lack of soaps in departments, majority of HCWs not receiving training on hand hygiene and very few alcohol hand rubs in departments. Waste segregation and waste management was poor, very few had been trained and majority were not aware of the guidelines.

\section{Acknowledgment}

I give my special thanks to my supervisors Dr Peterson Warutere and Dr Stanley Kimuhu for their guidance and advice. I also extend my gratitude to Kenyatta University ethics and research committee for granting me the research approval. I sincerely thank the Embu County Health Department and Embu Level 5 Hospital for granting me permission to carry out the study. I wish to thank my data collection assistants and all the respondents who consented and participated in this study.

\section{REFERENCES}

1. WHO (2014); Observations of infection prevention and control practices in primary health care, Kenya. Retrieved from https://www.who.int/bulletin/volumes/95/7/16-179499/en.

2. CDC (2011); Guideline for Isolation Precautions: Preventing Transmission of Infectious Agents in Healthcare Settings.

3. MOH (2016). National Infection Prevention and Control Guidelines, Kenya, 2016).

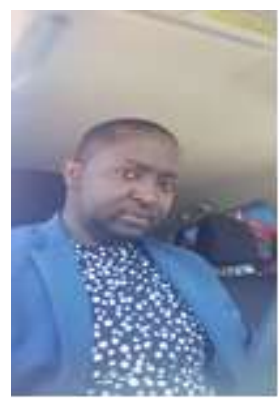

About the author

Richard mulu musyoki, a student in kenyatta university with interest in public health research area

Department of Community Health and Epidemiology

School of Public Health and Applied Human Sciences

Kenyatta University

Nairobi, Kenya

Email adress: $\underline{\text { rmusyoki8@ gmail.com }}$ 